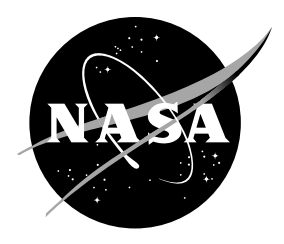

\title{
The Effect of Modified Control Limits on the Performance of a Generic Commercial Aircraft Engine
}

Jeffrey T. Csank

Glenn Research Center, Cleveland, Ohio

Ryan D. May

ASRC Aerospace Corporation, Cleveland, Ohio

Ten-Huei Guo and Jonathan S. Litt

Glenn Research Center, Cleveland, Ohio 


\section{NASA STI Program . . . in Profile}

Since its founding, NASA has been dedicated to the advancement of aeronautics and space science. The NASA Scientific and Technical Information (STI) program plays a key part in helping NASA maintain this important role.

The NASA STI Program operates under the auspices of the Agency Chief Information Officer. It collects, organizes, provides for archiving, and disseminates NASA's STI. The NASA STI program provides access to the NASA Aeronautics and Space Database and its public interface, the NASA Technical Reports Server, thus providing one of the largest collections of aeronautical and space science STI in the world. Results are published in both non-NASA channels and by NASA in the NASA STI Report Series, which includes the following report types:

- TECHNICAL PUBLICATION. Reports of completed research or a major significant phase of research that present the results of NASA programs and include extensive data or theoretical analysis. Includes compilations of significant scientific and technical data and information deemed to be of continuing reference value. NASA counterpart of peer-reviewed formal professional papers but has less stringent limitations on manuscript length and extent of graphic presentations.

- TECHNICAL MEMORANDUM. Scientific and technical findings that are preliminary or of specialized interest, e.g., quick release reports, working papers, and bibliographies that contain minimal annotation. Does not contain extensive analysis.

- CONTRACTOR REPORT. Scientific and technical findings by NASA-sponsored contractors and grantees.
- CONFERENCE PUBLICATION. Collected papers from scientific and technical conferences, symposia, seminars, or other meetings sponsored or cosponsored by NASA.

- SPECIAL PUBLICATION. Scientific, technical, or historical information from NASA programs, projects, and missions, often concerned with subjects having substantial public interest.

- TECHNICAL TRANSLATION. Englishlanguage translations of foreign scientific and technical material pertinent to NASA's mission.

Specialized services also include creating custom thesauri, building customized databases, organizing and publishing research results.

For more information about the NASA STI program, see the following:

- Access the NASA STI program home page at http://www.sti.nasa.gov

- E-mail your question via the Internet to help@ sti.nasa.gov

- Fax your question to the NASA STI Help Desk at $443-757-5803$

- Telephone the NASA STI Help Desk at 443-757-5802

- Write to: NASA Center for AeroSpace Information (CASI) 7115 Standard Drive Hanover, MD 21076-1320 
NASA/TM-2012-217261

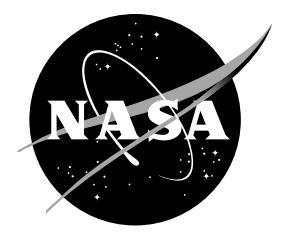

\section{The Effect of Modified Control Limits on the Performance of a Generic Commercial Aircraft Engine}

Jeffrey T. Csank

Glenn Research Center, Cleveland, Ohio

Ryan D. May

ASRC Aerospace Corporation, Cleveland, Ohio

Ten-Huei Guo and Jonathan S. Litt

Glenn Research Center, Cleveland, Ohio

Prepared for the

47th Joint Propulsion Conference and Exhibit

cosponsored by AIAA, ASME, SAE, and ASEE

San Diego, California, July 31-August 3, 2011

National Aeronautics and

Space Administration

Glenn Research Center

Cleveland, Ohio 44135 


\section{Acknowledgments}

The authors would like to thank Diana Drury of ASRC Aerospace Corporation, who handled the version control system for C-MAPSS40k. Our thanks also go to the NASA Aviation Safety Program’s Integrated Resilient Aircraft Control Project for funding this work.

Trade names and trademarks are used in this report for identification only. Their usage does not constitute an official endorsement, either expressed or implied, by the National Aeronautics and Space Administration.

Level of Review: This material has been technically reviewed by technical management.

Available from

NASA Center for Aerospace Information 7115 Standard Drive

Hanover, MD 21076-1320
National Technical Information Service 5301 Shawnee Road Alexandria, VA 22312

Available electronically at http://www.sti.nasa.gov 


\title{
The Effect of Modified Control Limits on the Performance of a Generic Commercial Aircraft Engine
}

\author{
Jeffrey T. Csank \\ National Aeronautics and Space Administration \\ Glenn Research Center \\ Cleveland, Ohio 44135 \\ Ryan D. May \\ ASRC Aerospace Corporation \\ Cleveland, Ohio 44135 \\ Ten-Huei Guo and Jonathan S. Litt \\ National Aeronautics and Space Administration \\ Glenn Research Center \\ Cleveland, Ohio 44135
}

\begin{abstract}
This paper studies the effect of modifying the control limits of an aircraft engine to obtain additional performance. In an emergency situation, the ability to operate an engine above its normal operating limits and thereby gain additional performance may aid in the recovery of a distressed aircraft. However, the modification of an engine's limits is complex due to the risk of an engine failure. This paper focuses on the tradeoff between enhanced performance and risk of either incurring a mechanical engine failure or compromising engine operability. The ultimate goal is to increase the engine performance, without a large increase in risk of an engine failure, in order to increase the probability of recovering the distressed aircraft. The control limit modifications proposed are to extend the rotor speeds, temperatures, and pressures to allow more thrust to be produced by the engine, or to increase the rotor accelerations and allow the engine to follow a fast transient. These modifications do result in increased performance; however this study indicates that these modifications also lead to an increased risk of engine failure.
\end{abstract}

\section{Nomenclature}

$\begin{array}{ll}50 \mathrm{hr} & 50 \text { Hour Engine (new) } \\ \text { Accel } & \text { Acceleration Limit (RPM/s) } \\ \text { C-MAPSS } & \text { Commercial Modular Aero-Propulsion System Simulation } \\ \text { C-MAPSS40k } & \text { Commercial Modular Aero-Propulsion System Simulation 40k } \\ \text { EGT } & \text { Exhaust Gas Temperature }\left({ }^{\circ} \mathrm{R}\right) \\ \text { EOL } & \text { End-of-Life Engine } \\ \text { EPR } & \text { Engine Pressure Ratio } \\ \text { MAS } & \text { Modified Acceleration Schedule } \\ \text { Mid } & \text { Mid Life Engine } \\ \text { Nc } & \text { Core Speed } \\ \text { Nf } & \text { Fan Speed } \\ \text { PI } & \text { Proportional Integral } \\ \text { Ps3 max } & \text { Maximum Combustor Static Pressure } \\ \text { Std } & \text { Standard Day Temperature }\left(59^{\circ} \mathrm{F}\right)\end{array}$




\subsection{Introduction}

There is interest in the ability to use an aircraft's engines to stabilize and control a distressed aircraft. It has been previously shown that in some emergencies the engines can serve as flight control actuators to improve the capabilities of the aircraft (Refs. 1 and 2). The ability of the aircraft's engines to produce thrust beyond their current limitations and to respond more quickly to the pilot's throttle command may result in an even greater likelihood of the recovery of a distressed aircraft. However, achieving elevated engine performance is complex due to limits that protect the mechanical system from severe structural damage such as rotor disk burst, and operability limits that ensure safe aero-thermal engine operation such as avoiding compressor surge. A risk performance study is conducted using the Commercial Modular Aero-Propulsion System Simulation 40k (C-MAPSS40k) to determine the tradeoff associated with extending or removing the engine controller's limits and allowing the engine to operate beyond its nominal design range. This performance/risk study addresses two types of engine performance enhancements: 1) overthrust, where limits are relaxed/removed to allow the engine to produce additional thrust, and 2) faster engine response, where the limits and the controller bandwidth are modified to improve the responsiveness of the engine to the pilot's throttle command. The two engine performance enhancements are in response to different aircraft emergency scenarios; these are not the only possible scenarios but are used as examples for these studies. The overthrust enhancement is in response to a runway incursion during takeoff, where the available distance for lift-off is suddenly decreased. Ideally, the additional thrust will accelerate the vehicle faster allowing the aircraft to takeoff with less available runway. The faster engine response enhancement tries to compensate for a rudder/tail failure, where the effectiveness of the rudder control surface or vertical stabilizer is reduced. This performance enhancement has been shown to enable the engines to behave dynamically as the control surface. More information about these scenarios can be found in Reference 3.

Engine performance is purposely restricted through conservative controller design practices which are necessary to provide safe operation and consistent performance throughout the flight envelope and to conserve the life of engine components. However, in emergency situations the need to preserve safety margins can be traded for increased engine performance, which improves the survivability of the aircraft. This type of tradeoff is only considered for high risk situations; situations in which the aircraft is not capable of being flown safely. The ultimate goal of this work is to be able to subject the distressed aircraft to the minimum risk through the use of the enhanced propulsion control system; this is beyond the scope of this paper and more information about this topic is available in Reference 4 . This analysis is limited to gaining an understanding of how engine risk is affected by changes to the engine controller limits.

Previous work investigated the ability to obtain additional performance from a commercial aircraft engine. Reference 3 described a sensitivity study using the Commercial Modular Aero-Propulsion System Simulation (C-MAPSS), a model of a 90,000 lb thrust class engine. Reference 5 contains detailed results for a sensitivity study using C-MAPSS40k, a 40,000 lb thrust class engine. For the overthrust scenario, References 3 and 5 both conclude that to obtain additional thrust other engine variables will have to increase, possibly beyond their limits. However, neither reference identifies a generic tradeoff between enhanced engine performance and increased risk of operation. Reference 5 does show a trend based on a few flight conditions, but does not capture the entire performance/risk tradeoff that exists with the simulation model/risk calculations. Both References 3 and 5 discuss modifications to achieve increased engine responsiveness and they identify a subsequent reduction in either closed-loop stability margins or high pressure compressor surge margin; however these results are specific to flight conditions and are not generic. This performance/risk study attempts to determine the impact on the engine, in terms of risk of an engine failure incurred when providing additional performance, either overthrust production or increased engine responsiveness.

This study is performed with the C-MAPSS40k engine. Details of this simulation and an overview of the engine controller is provided in Section 2.0. The results of the overthrust scenario are contained in Section 3.0, while the faster engine response results are in Section 4.0. Section 5.0 contains general conclusions. 


\subsection{Engine Control Overview}

This performance/risk study is conducted using the C-MAPSS40k engine simulation. C-MAPSS40k is a 40,000 lb thrust class, two spool, physics-based, component level, high bypass turbofan engine simulation with an associated closed loop controller. This engine simulation is modeled in the MATLAB/Simulink (The MathWorks, Inc.) environment (Ref. 6).

The C-MAPSS40k engine control system regulates Engine Pressure Ratio (EPR), which is the low pressure turbine exit pressure divided by the engine inlet pressure. EPR is directly related to the thrust produced by the engine. The aircraft engine control system converts the pilot's throttle command from a desired thrust level (idle, flight idle, take-off power, etc.) to an EPR setpoint, which is also affected by the current flight condition (altitude, Mach, and temperature). A setpoint controller responds to the EPR error, which is the difference between the setpoint and sensed EPR feedback, and drives the engine to the requested power level. In C-MAPSS40k, the setpoint controller features a Proportional Integral controller with integral wind-up protection. The setpoint controller determines the dynamic response of the engine to a throttle transient.

Controller protection logic ensures that the setpoint controller will not cause the engine to violate any of its limits. This logic compares select engine sensed measurements against defined operating limits and, if necessary, adjusts fuel flow rate to rectify any limit exceedances. The C-MAPSS40k limiters include: maximum fan speed, maximum core speed, maximum combustor static pressure, maximum core shaft acceleration (based on an acceleration schedule), minimum combustor static pressure, and minimum ratio unit (fuel flow rate divided by the static combustor pressure). More information regarding aircraft engine control and the scheme employed in C-MAPSS40k can be found in Reference 7. In order for the results of this study to have the widest applicability, the study will maintain the existing control system architecture and only modify the control limit values. The general method employed in the study is to remove various limiters and observe the resulting change in engine performance.

\subsection{Overthrust}

In the overthrust scenario, Reference 3 found that the engine outputs such as rotor speeds, turbine temperatures, and compressor pressures, varied nearly linearly with the throttle input, and that the engine limits may need to be increased in order for the C-MAPSS engine to meet the overthrust demand. Reference 5 found that increasing the thrust demand resulted in a shift in the C-MAPSS40k engine outputs, although the shift is not necessarily linear. Reference 5 also found that increasing the engine's thrust output resulted in increasing the risk of an engine failure, which is also dependent on the amount of time spent operating at the overthrust condition. An outcome of the Reference 5 study was the addition of a turbine temperature limiter designed to allow the temperature limit to be decreased based on the expected time of operation.

In the overthrust scenario, the pilot requests additional thrust from the aircraft's engines. To facilitate this, the EPR setpoints are extended to higher levels. For this study, the EPR setpoints are extended to correlate to 120 percent of the maximum rated thrust. In addition, the maximum fan speed, maximum core speed, and maximum combustor pressure limits are extended to 150 percent of their nominal values to allow the engine to reach the elevated EPR setpoint. A preliminary risk function has been implemented, which is similar to the one proposed in Reference 8, to evaluate the change in risk with operating at the higher power levels. This risk function, which is a probabilistic model of engine life as a function of operating condition, determines the probability of any mechanical engine failure. The engine is designed to have a certain life at a given probability of failure based on expected usage, and increasing the operating speed and temperature increases the risk of failure. The risk function is based on relationships between speed, temperature, and life consumption, and evaluates risk based on the anticipated overthrustrelated operating conditions. As the engine runs, life is consumed increasing the risk of failure, and use of an overthrust control mode, because of the increased speeds and temperatures, consumes life significantly faster than normal. This reduction in engine life, combined with the current estimate of the engine 
condition, determines the overall risk of engine failure. The overthrust scenario in this paper concentrates on takeoff, therefore the operating time used in the risk calculations is $15 \mathrm{~min}$.

The risk of engine failure is dependent on the flight condition (altitude, Mach number, and ambient temperature) as well as engine deterioration level. Therefore, in this performance/risk study the altitude, Mach number, ambient temperature, and engine deterioration level will be varied to determine the engine risk factor trends for different power levels. Figure 1 contains risk factor plots for two different airport elevations. This includes one airport at 5,431 ft above sea level (elevation at Denver International Airport) and a second airport at 2,181 ft above sea level (elevation at McCarran International Airport in Las Vegas, NV). Each of these plots show the risk factor for different power level commands (Full Power Throttle, \%) for a new $50 \mathrm{hr}$ engine, a mid-life engine (Mid), and an end-of-life engine (EOL) on both standard days (Std) and hot days (59 and $109^{\circ} \mathrm{F}$ at sea level, respectively).

Based on the data shown in Figure 1, generic observations regarding risk/performance tradeoff based on flight condition and engine life can be made. First, the elevation at which the power request is made plays a major role. This is shown by comparing the risk factor at 120 percent Max Power between the two different elevations. At the higher elevation airport (Denver), the risk factor is more than 10 times the risk factor at the lower elevation airport (McCarran). This is due to decreased air density at higher elevations, which decreases thrust production. Therefore, for the engine to produce the required thrust for takeoff, the engine has to operate at higher speeds and hotter temperatures. Another major contributor to the risk of engine failure is the ambient temperature. In both plots shown in Figure 1, the shape of the risk curve changes based on ambient temperature (comparing the blue lines to the red lines), and the risk at 120 percent Max Power increases by a factor of 10 or more from a standard to a hot day. This effect is again due to decreased air density on hotter days. As the ambient temperature increases, the air density decreases. This again requires the engine to operate at higher speeds and temperatures to produce the thrust required for takeoff. Increased engine deterioration levels will cause an increase in the risk factor, but the increase is rather small compared to the effects of ambient temperature and elevation. As the engine degrades, the risk factor increases due to the components reaching their end of life; operating at the same altitude, ambient temperature, and EPR results in an increased risk of failure due to the fact that much of the component life has already been consumed. Furthermore, a degraded engine runs hotter, which also contributes to increased risk.

\section{Denver International Airport (5,431 ft)}

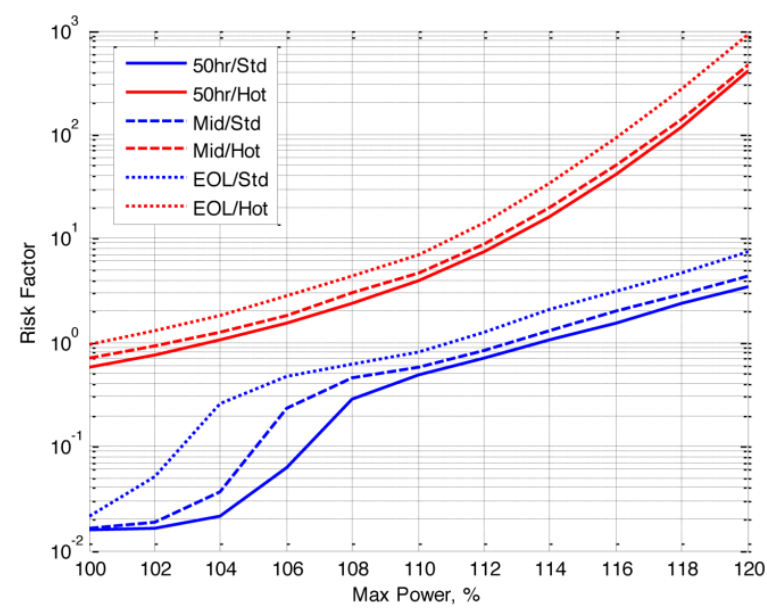

\section{McCarran International Airport (2,181 ft)}

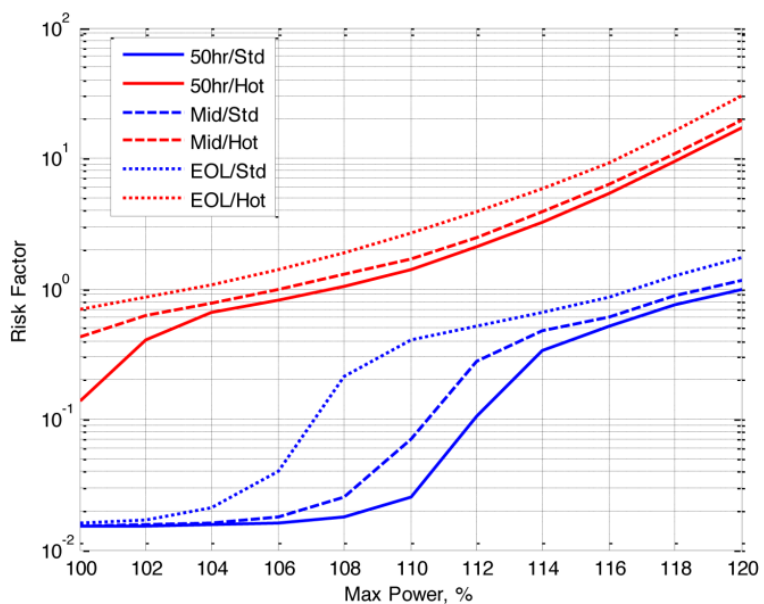

Figure 1.-Comparison of risk factor for varying power level, engine life, and temperature, at two different elevations $(5,431$ and 2,181 ft), both at Mach 0.15. 


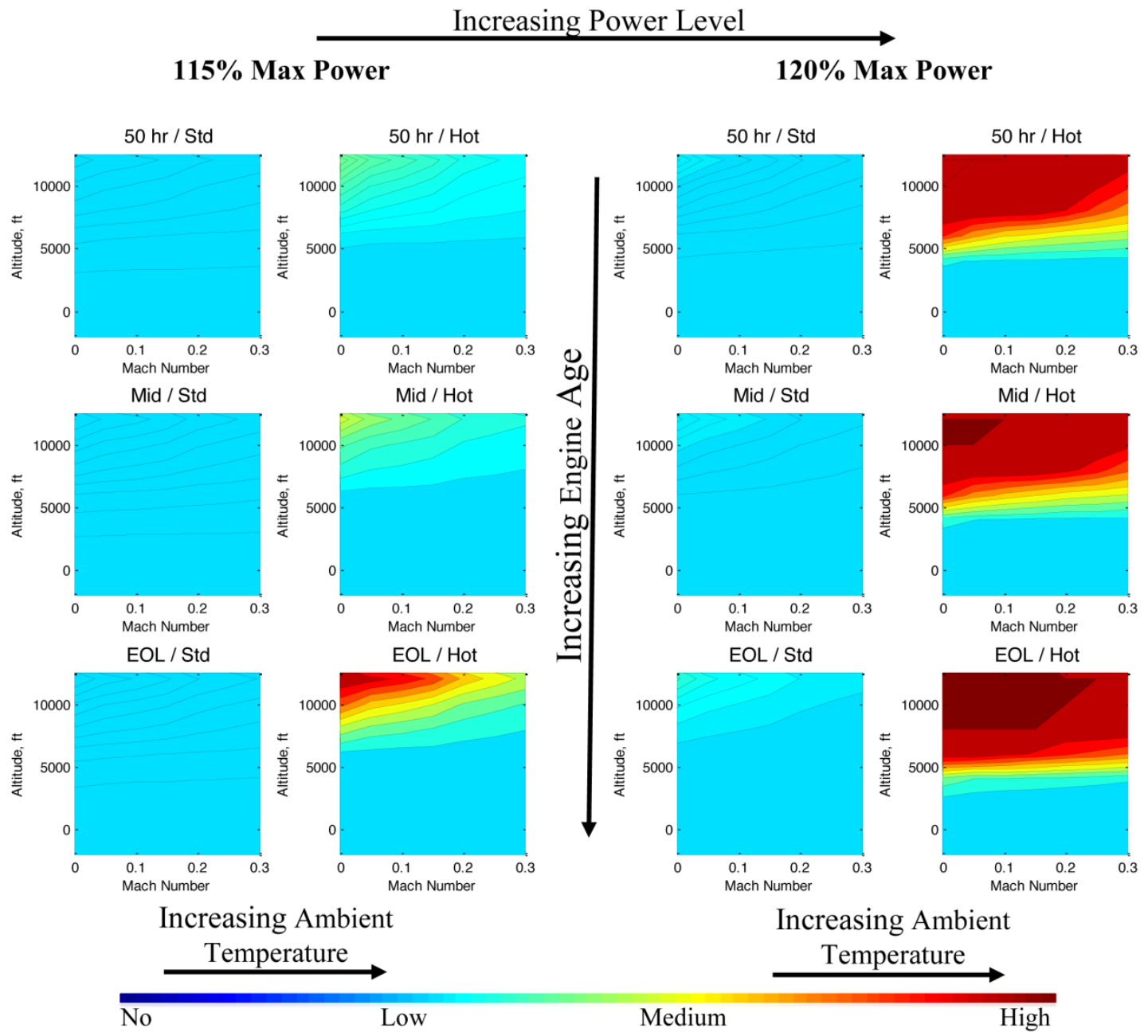

Figure 2.--Risk factor for varying takeoff conditions (altitude ( $\mathrm{ft}$ ), Mach number, ambient temperature, and engine age) for two power levels (115 percent max power and 120 percent max power). Note that the pilots' predominant control is engine power level, all other parameters (altitude, Mach number, ambient temperature, and engine life) are essentially fixed; determined by the takeoff location (airport), the current local weather (temperature), and engine age.

This type of evaluation can be extended to include many different takeoff conditions, by varying Mach number, altitude, ambient temperature, and power levels. Figure 2 compares the risk factor (as a contour plot) for varying altitude, Mach number, temperature, and engine deterioration level. The two plots shown in Figure 2 correspond to different power levels, 115 percent Max Power (left) and 120 percent Max Power (right).

The data in Figure 2 again show the effect of the ambient temperature on risk of failure. Comparing the two columns for each power level, a large change in the risk factor exists based on the temperature. Comparing the power levels, the data show that increasing the power level from 115 percent max power to 120 percent max power greatly increases the risk on hotter days, but not as much on standard days. Another observation is that at altitudes greater than $5,000 \mathrm{ft}$, the risk factor is increased drastically more compared to the lower altitudes. This suggests that at airports with an elevation of less than 3,000 ft, increasing the thrust output of the engine for takeoff maybe very practical due to the relatively low increase in risk. However, at higher altitude airports, such as at Denver (altitude 5,431 ft), additional thrust may not be justified based on the increased risk level. These plots also indicate, as did the plots shown in Figure 1 that the engine life plays a minor role in increasing the risk of failure compared to the ambient temperature and altitude. 


\subsection{Faster Engine Response}

Increasing the responsiveness of the engine can be divided into two separate categories, one for small throttle transients and the other for large throttle transients. For the small throttle transients, Reference 3 found that both increasing the controller bandwidth and disabling the controller limits allowed for a significant reduction in the settling time. Reference 5 however found that increasing the bandwidth alone was enough to increase the engine responsiveness since none of the limits become active for small throttle transients in C-MAPSS40k. The difference between these two findings can be attributed to a structural difference between the C-MAPSS controller, which was used in the previous studies, and the C-MAPSS40k controller protection logic. The C-MAPSS controller has an upper and lower bound on the change in fuel flow, limiting the acceleration based on change in fuel flow, whereas C-MAPSS40k limits the acceleration based on the current core speed of the engine and the magnitude of the change.

Regarding large throttle transients, Reference 3 found that relaxing the turbine temperature limit, modifying the acceleration schedule, and increasing the controller bandwidth increased the engine responsiveness. Reference 5 proposed a Modified Acceleration Schedule (MAS), which is a look up table based method where an offset is added to the nominal acceleration schedule. This offset will increase the acceleration schedule resulting in a faster responding engine.

The purpose of the faster engine response operation is to decrease the lag between the pilot's command and engine response. In an emergency situation, such as a rudder/tail failure as the aircraft is approaching the runway, the pilot may find it necessary to execute a go around (abort the landing) and re-attempt the approach. For this type of maneuver, the pilot will move the throttle from flight idle (very low power level used during the approach) to takeoff thrust very quickly. In this type of situation, the acceleration schedule commands a conservative engine response to prevent high pressure compressor surge. The acceleration schedule in C-MAPSS40k is designed to ensure that the high pressure compressor surge margin is greater than 0.0 for a full throttle transient regardless of the flight condition (as long as the flight condition is inside the flight envelope) or the engine deterioration level.

To increase the responsiveness of the engine for this type of command, the acceleration schedule may be modified to allow higher core acceleration, resulting in a faster engine response and decreased high pressure compressor surge margin. The modification of the acceleration schedule can be done from a lookup table that determines the acceleration schedule bias based on the flight condition and the engine deterioration level. This look up table method is referred to as Modified Acceleration Schedule (MAS) (Ref. 5). The nominal control response, referring to the engine response with no changes made to the controller, and MAS control responses to a full throttle transient with a $50 \mathrm{hr}$ engine and an end-of-life engine are shown in Figure 3.

50 Hour Engine
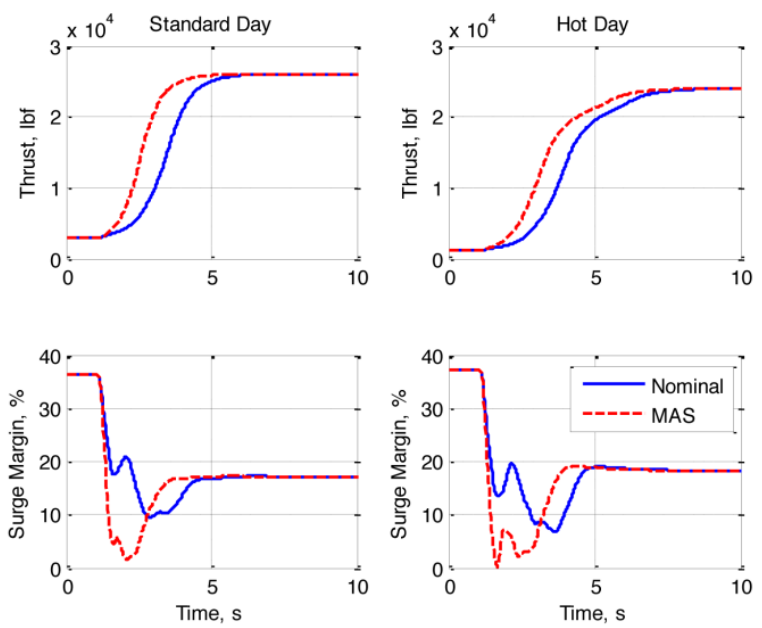

End of Life Engine
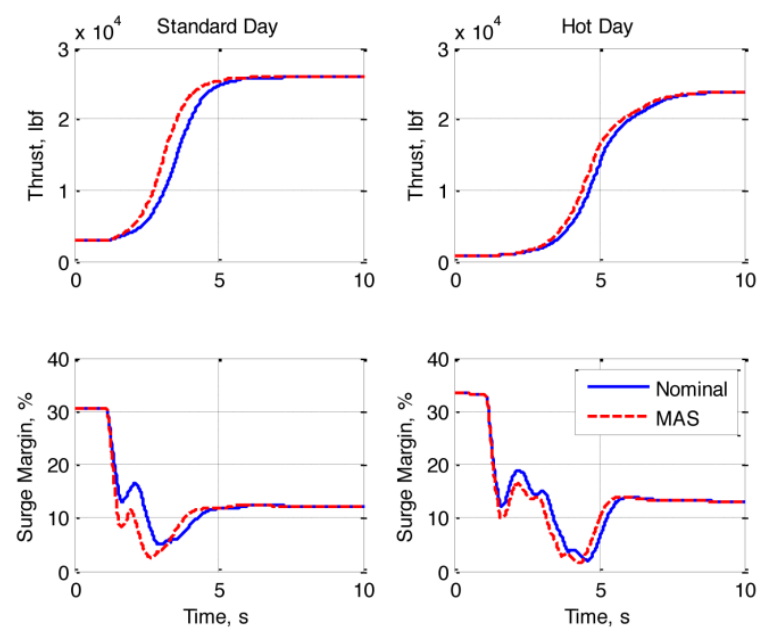

Figure 3.-Engine responses to a full throttle transient for varying ambient temperature and engine degradation. 
Figure 3 indicates that an increase in the ambient temperature will increase the settling time for the nominal control by about $2 \mathrm{sec}$. Considering the nominal control response between a $50 \mathrm{hr}$ engine and an end of life engine for the same ambient temperature, the thrust response is nearly independent of engine life. However, a reduction in engine life will decrease the surge margin; in Figure 3 the surge margin is reduced by about 4 percent over the entire life of the engine. Since the MAS control method of increasing the responsiveness trades surge margin for responsiveness, flight conditions and engine degradation levels that have the most surge margin available will be capable of larger thrust response improvements. This is very apparent in Figure 3; the condition with the largest surge margin reduction has the greatest performance increase. In this example, the MAS was designed such that the resulting surge margin never fell below 2 to 3 percent. The MAS was successful in 3 of the 4 scenarios, the surge margin for a $50 \mathrm{hr}$ engine on a hot day decreased to below 2 percent, but stayed above 0 percent. This is due to nonlinearities in the engine and inaccuracies in the lookup table method.

One of the uncertainties that the acceleration schedule must account for is normal engine-to-engine variation. Since a less than average engine must be able to accelerate safely, the acceleration schedule must be designed to accommodate a 3 sigma variation in surge margin to essentially guarantee that no engine will surge. If the engine-to-engine variation in surge margin is normally distributed with a standard deviation of 1 percent, then in the worst case 99.86 percent of all engines will accelerate safely for a 3 percent designed minimum surge margin. Any adjustment of the acceleration schedule for faster engine response means that the below average engines are more likely to surge. The impact of the 3-sigma variation on faster engine response and surge margin in run-time can be seen in Figure 4. Figure 4 compares the nominal control and MAS control surge margin response for the $50 \mathrm{hr}$ engine on a standard day, the same response as shown in Figure 3, but with the 3 sigma variation around the surge margin. The lower bound on the surge margin in Figure 4 represents 99.86 percent of all $50 \mathrm{hr}$ engines. By increasing the acceleration schedule to allow the surge margin responses shown in Figure 4, it is clear that there are $50 \mathrm{hr}$ engines in the fleet that would surge. When modifying the acceleration schedule, the risk is inversely related to the likelihood that the aircraft's engines are better than an average $50 \mathrm{hr}$ engine. The more likely that the engine is better than average, the greater the available surge margin and the less risky is the modification of the acceleration schedule. The second part of the risk is how much to increase the
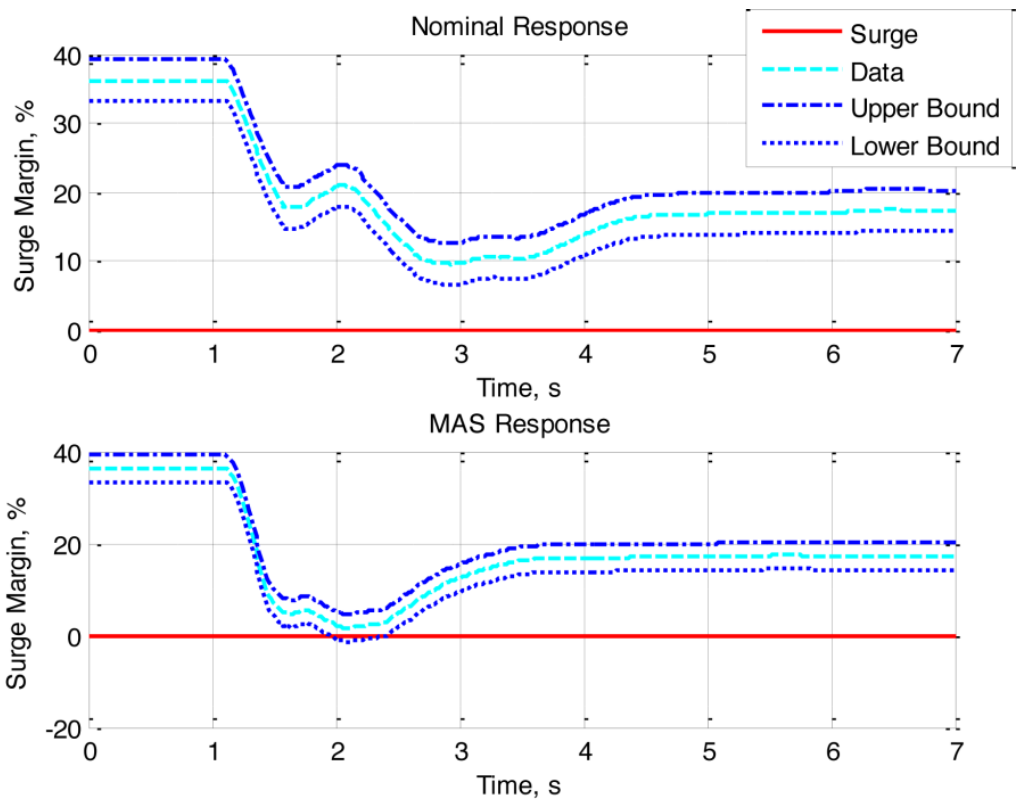

Figure 4.- Surge Margin for $50 \mathrm{hr}$ engine undergoing full throttle transient with nominal control and MAS control. 
acceleration schedule, or how low to reduce the surge margin for an average engine. The more confidence there is that the engine is an average engine or better, the more the acceleration schedule can be increased, decreasing the engine surge margin closer to zero. However, if there is no confidence that the engine is an average engine or better, then the acceleration schedule modification may have to be more conservative.

The C-MAPSS40k setpoint controller for EPR is a PI controller that dominates the response for smaller throttle transients that are unaffected by the acceleration limiter. The performance for these transients can be enhanced by increasing the bandwidth of the PI controller. The concern with increasing the bandwidth of the PI controller is decreasing stability margins (gain margin and phase margin) and actually decreasing the performance of the engine. A decrease in the stability margins can result in a decrease in performance, in terms of increased settling time, increased overshoot (below 2 percent is considered acceptable), and increased rise time. The only performance metric that may not be affected by the decrease in stability margins is the delay time, or the time it takes for the engine to respond to the throttle command. Figure 5 shows the settling time, percent overshoot, delay time, and rise time performance metrics as a function of the PI gain multiplier (bandwidth increase). The data were taken at altitudes from 0 to 28,000 ft in 4,000 ft increments, 0.0 to 0.7 Mach in 0.1 Mach increments, on both standard and hot days, and for a $50 \mathrm{hr}$ engine, a mid life engine, and an end-of-life engine.

The data in Figure 5 suggest that the PI controller gains can be increased, but only by a factor of about 1.5. Increasing the gains by more than this may decrease the performance of the engine, which is shown in Figure 5 by the increase in settling time for multipliers greater than 1.5, an increase in the overshoot (above 2 percent) for multipliers greater than 2.5, and increased rise times for multipliers greater than approximately 1.5. The delay time improves for almost all of the tested data points, but does start to diverge after a multiplier of 3 . This shows that it is possible to obtain additional performance from the engine by increasing controller gains; however there is a risk that the increased controller gains will actually decrease the performance of the engine, making the situation worse.
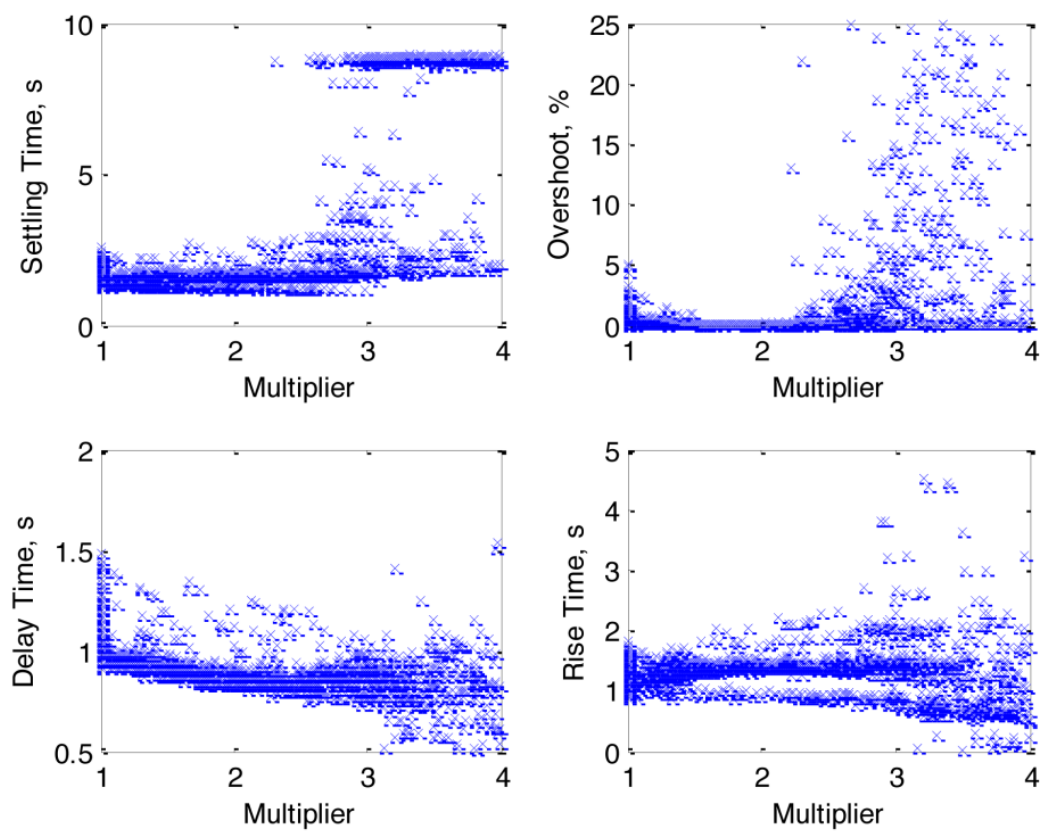

Figure 5.-Performance for small throttle transients for various PI gain multipliers. 


\subsection{Conclusions}

This paper discussed approaches to achieve enhanced engine performance and showed results from the application of these approaches to a turbofan engine simulation, C-MAPSS40k. For overthrust, the amount of additional thrust produced by the engine was compared to the risk factor, or the ratio of the risk of an engine failure caused by the use of additional thrust to the maximum normal operating risk. This study determined that altitude and ambient temperature are the two most significant factors in increasing the risk of an engine failure, especially as the amount of overthrust increases. At lower altitudes, even on a hot day, there was low to medium increase in risk to produce 120 percent maximum thrust. For the faster engine response, there were two different tradeoffs to compare depending on the size of the throttle transient. For large throttle transients, which are affected by the acceleration schedule, the acceleration schedule may be increased; this results in faster response and decreased settling time, but at the cost of decreasing the surge margin, which is directly related to the risk of an engine failure. The maximum benefit can be achieved with newer or above average engines, while similar performance improvement is much riskier with deteriorated engines. For smaller throttle transients, which are unaffected by the acceleration schedule, improved response speed is accomplished by increasing the controller bandwidth. However this will actually decrease stability margins to the point where the performance is degraded. Based on the observations in this paper, the controller bandwidth can be increased up to 1.5 times the current level with little risk of performance degradation. These results show that it is possible, under the right conditions, to achieve significantly increased performance with little risk of engine failure, although improvement is severely limited without a significant risk increase in other cases. Understanding what the capabilities and limitations are can lead to new control algorithms to improve engine performance relatively safely. These conclusions are specific to the C-MAPSS40k type engine and controller, however the methodology in this paper can be used to evaluate the trade-offs for different engines and different controller architectures.

\section{References}

1. Burcham, F.W., Jr., and Fullerton, C.G., "Controlling Crippled Aircraft - With Throttles," NASA/TM-104238, 1991.

2. Burcham, F.W., Jr., Fullerton, C.G., and Maine, T.A., "Manual Manipulation of Engine Throttles for Emergency Flight Control,” NASA/TM-2004-212045, January 2004.

3. Litt, J.S., Frederick, D.K., and Guo, T.-H, “The Case for Intelligent Propulsion Control for Fast Engine Response,” AIAA-2009-1876, AIAA Infotech@Aerospace Conference, Seattle WA, June 6-9, 2009.

4. McGlynn, G.E., Litt, J.S., Lemon, K.A., and Csank, J.T., “A Risk Management Architecture for Emergency Integrated Aircraft Control,” AIAA-2011-1568, Infotech@Aerospace 2011, St. Louis, Missouri, Mar. 29-31, 2011.

5. Csank, J.T., May, R.D., Litt, J.S., and Guo, T.-H., "A Sensitivity Study of Commercial Aircraft Engine Response for Emergency Situations,” NASA/TM-2011-217004, April 2011.

6. May, R.D., Csank, J., Lavelle, T.M., Litt, J.S., and Guo, T.-H, “A High-Fidelity Simulation of a Generic Commercial Aircraft Engine and Controller," $46^{\text {th }}$ AIAA/ASME/SAE/ASEE Joint Propulsion Conference \& Exhibit, Nashville, TN, July 25-28 2010.

7. Csank, J., May, R.D., Litt, J.S., and Guo, T.-H., "Control Design for a Generic Commercial Aircraft Engine,” AIAA-2010-6629, 46th AIAA/ASME/SAE/ASEE Joint Propulsion Conference and Exhibit, Nashville, TN, July 25-28, 2010.

8. Litt, J.S., Sharp, L.M., Guo, T.-H., “A Risk Assessment Architecture for Enhanced Engine Operation,” AIAA-2010-3469, AIAA Infotech@Aerospace 2010, Atlanta, GA, April 20-22, 2010. 


\begin{tabular}{|c|c|c|c|c|c|}
\hline \multicolumn{5}{|c|}{ REPORT DOCUMENTATION PAGE } & $\begin{array}{l}\text { Form Approved } \\
\text { OMB No. 0704-0188 }\end{array}$ \\
\hline \multicolumn{6}{|c|}{$\begin{array}{l}\text { The public reporting burden for this collection of information is estimated to average } 1 \text { hour per response, including the time for reviewing instructions, searching existing data sources, gathering and maintaining the } \\
\text { data needed, and completing and reviewing the collection of finformation. Send comments regarding this burden estimate or any other aspect of this collection of information, including suggestions for reducing this } \\
\text { burden, to Department of Defense, Washington Headquarters Services, Directorate for Information Operations and Reports (0704-0188), 1215 Jefferson Davis Highway, Suite } 1204 \text {, Arlington, VA } 22202-4302 \text {. } \\
\text { Respondents should be aware that notwithstanding any other provision of law, no person shall be subject to any penalty for failing to comply with a collection of information if it does not display a currently valid OMB } \\
\text { control number. } \\
\text { PLEASE DO NOT RETURN YOUR FORM TO THE ABOVE ADDRESS. }\end{array}$} \\
\hline \multicolumn{2}{|c|}{$\begin{array}{l}\text { 1. REPORT DATE (DD-MM-YYYY) } \\
01-01-2012\end{array}$} & \multicolumn{3}{|c|}{$\begin{array}{l}\text { 2. REPORT TYPE } \\
\text { Technical Memorandum }\end{array}$} & 3. DATES COVERED (From - To) \\
\hline \multirow{3}{*}{\multicolumn{5}{|c|}{$\begin{array}{l}\text { 4. TITLE AND SUBTITLE } \\
\text { The Effect of Modified Control Limits on the Performance of a Generic Commercial Aircra } \\
\text { Engine }\end{array}$}} & 5a. CONTRACT NUMBER \\
\hline & & & & & 5b. GRANT NUMBER \\
\hline & & & & & 5c. PROGRAM ELEMENT NUMBER \\
\hline \multirow{3}{*}{\multicolumn{5}{|c|}{$\begin{array}{l}\text { 6. AUTHOR(S) } \\
\text { Csank, Jeffrey, T.; May, Ryan, D.; Guo, Ten-Huei; Litt, Jonathan, S. }\end{array}$}} & 5d. PROJECT NUMBER \\
\hline & & & & & 5e. TASK NUMBER \\
\hline & & & & & $\begin{array}{l}\text { 5f. WORK UNIT NUMBER } \\
\text { WBS 284848.02.05.03.10 }\end{array}$ \\
\hline \multicolumn{5}{|c|}{$\begin{array}{l}\text { 7. PERFORMING ORGANIZATION NAME(S) AND ADDRESS(ES) } \\
\text { National Aeronautics and Space Administration } \\
\text { John H. Glenn Research Center at Lewis Field } \\
\text { Cleveland, Ohio 44135-3191 }\end{array}$} & $\begin{array}{l}\text { 8. PERFORMING ORGANIZATION } \\
\text { REPORT NUMBER } \\
\text { E-18017 }\end{array}$ \\
\hline \multirow{2}{*}{\multicolumn{5}{|c|}{$\begin{array}{l}\text { 9. SPONSORING/MONITORING AGENCY NAME(S) AND ADDRESS(ES) } \\
\text { National Aeronautics and Space Administration } \\
\text { Washington, DC 20546-0001 }\end{array}$}} & $\begin{array}{l}\text { 10. SPONSORING/MONITOR'S } \\
\text { ACRONYM(S) } \\
\text { NASA }\end{array}$ \\
\hline & & & & & $\begin{array}{l}\text { 11. SPONSORING/MONITORING } \\
\text { REPORT NUMBER } \\
\text { NASA/TM-2012-217261 }\end{array}$ \\
\hline \multicolumn{6}{|c|}{$\begin{array}{l}\text { 12. DISTRIBUTIONIAVAILABILITY STATEMENT } \\
\text { Unclassified-Unlimited } \\
\text { Subject Categories: } 07 \text { and } 63 \\
\text { Available electronically at http://www.sti.nasa.gov } \\
\text { This publication is available from the NASA Center for AeroSpace Information, 443-757-5802 }\end{array}$} \\
\hline \multicolumn{6}{|c|}{ 13. SUPPLEMENTARY NOTES } \\
\hline \multicolumn{6}{|c|}{$\begin{array}{l}\text { 14. ABSTRACT } \\
\text { This paper studies the effect of modifying the control limits of an aircraft engine to obtain additional performance. In an emergency } \\
\text { situation, the ability to operate an engine above its normal operating limits and thereby gain additional performance may aid in the recovery } \\
\text { of a distressed aircraft. However, the modification of an engine’s limits is complex due to the risk of an engine failure. This paper focuses } \\
\text { on the tradeoff between enhanced performance and risk of either incurring a mechanical engine failure or compromising engine operability. } \\
\text { The ultimate goal is to increase the engine performance, without a large increase in risk of an engine failure, in order to increase the } \\
\text { probability of recovering the distressed aircraft. The control limit modifications proposed are to extend the rotor speeds, temperatures, and } \\
\text { pressures to allow more thrust to be produced by the engine, or to increase the rotor accelerations and allow the engine to follow a fast } \\
\text { transient. These modifications do result in increased performance; however this study indicates that these modifications also lead to an } \\
\text { increased risk of engine failure. }\end{array}$} \\
\hline \multicolumn{6}{|c|}{$\begin{array}{l}\text { 15. SUBJECT TERMS } \\
\text { Control; Propulsion control; Sensitivity analysis }\end{array}$} \\
\hline \multicolumn{3}{|c|}{ 16. SECURITY CLASSIFICATION OF: } & $\begin{array}{l}\text { 17. LIMITATION OF } \\
\text { ABSTRACT }\end{array}$ & $\begin{array}{l}\text { 18. NUMBER } \\
\text { OF }\end{array}$ & $\begin{array}{l}\text { 19a. NAME OF RESPONSIBLE PERSON } \\
\text { STI Help Desk (email:help@sti.nasa.gov) }\end{array}$ \\
\hline $\begin{array}{l}\text { a. REPORT } \\
\text { U }\end{array}$ & $\begin{array}{l}\text { b. ABSTRACT } \\
\text { U }\end{array}$ & $\begin{array}{l}\text { c. THIS } \\
\text { PAGE } \\
\text { U }\end{array}$ & UU & $\begin{array}{l}\text { PAGES } \\
15\end{array}$ & $\begin{array}{l}\text { 19b. TELEPHONE NUMBER (include area code) } \\
443-757-5802\end{array}$ \\
\hline
\end{tabular}



